\title{
Mechanochemical Synthesis of Sn(II) and Sn(IV) Iodide Perovskites and Study of Their Structural, Chemical, Thermal, Optical and Electrical Properties
}

Yousra El Ajjouri, Federico Locardi, María C. Gélvez-Rueda, Mirko Prato, Michele Sessolo, Maurizio Ferretti, Ferdinand C. Grozema, Francisco Palazon* and Henk J. Bolink

Y. El Ajjouri, Dr. M. Sessolo, Dr. F. Palazon, Prof. H. J. Bolink

Instituto de Ciencia Molecular, ICMol, Universidad de Valencia

C/ Catedrático J. Beltrán 2, 46980 Paterna, Spain

E-mail: Francisco.palazon@uv.es

Dr. F. Locardi, Prof. M. Ferretti

Dipartimento di Chimica e Chimica Industriale, Università degli Studi di Genova

Via Dodecaneso 31, 16146 Genova, Italy

Dr. F. Locardi, Dr. F. Palazon

Nanochemistry Department, Istituto Italiano di Tecnologia

Via Morego 30, 16163 Genova, Italy

M. C. Gélvez-Rueda, Dr. F. C. Grozema

Optoelectronic Materials Section, Department of Chemical Engineering, Delft University of Technology

Van der Maasweg 9, 2629 HZ Delft, The Netherlands

Dr. M. Prato,

Materials Characterization Facility, Istituto Italiano di Tecnologia

Via Morego 30, 16163 Genova, Italy

Keywords: perovskites, mechanochemistry, solid-state, tin, low-bandgap

Phase-pure $\mathrm{CsSnI}_{3}, \mathrm{FASnI}_{3}, \mathrm{Cs}(\mathrm{PbSn}) \mathrm{I}_{3}, \mathrm{FA}(\mathrm{PbSn}) \mathrm{I}_{3}$ perovskites $(\mathrm{FA}=$ formamidinium $=$ $\left.\mathrm{HC}\left(\mathrm{NH}_{2}\right)_{2}{ }^{+}\right)$as well as the analogous so-called "vacancy-ordered double perovskites" $\mathrm{Cs}_{2} \mathrm{SnI}_{6}$ and $\mathrm{FA}_{2} \mathrm{SnI}_{6}$ were mechanochemically synthesized. The addition of $\mathrm{SnF}_{2}$ was found to be crucial for the synthesis of Cs-containing perovskites but unnecessary for hybrid ones. All compounds show an absorption onset in the near-IR region, which makes them especially relevant for photovoltaic applications. The addition of $\mathrm{Pb}(\mathrm{II})$ and $\mathrm{SnF}_{2}$ is crucial to improve the electronic properties in 3D Sn(II)-based perovskites, in particular their charge carriers mobility $\left(\sim 0.2 \mathrm{~cm}^{2} /\right.$ V.s $)$ which is enhanced upon reduction of the dark carrier conductivity.

This article has been accepted for publication and undergone full peer review but has not been through the copyediting, typesetting, pagination and proofreading process, which may lead to differences between this version and the Version of Record. Please cite this article as doi: $10.1002 /$ ente.201900788 


\section{WILEY-VCH}

Stokes-shifted photoluminescence is observed on dry powders of Sn(II)-based perovskites, which makes these materials promising for light-emitting and sensing applications. Thermal stability of all compounds has been examined, revealing no significant degradation up to at least $200{ }^{\circ} \mathrm{C}$. This meets the requirements for standard operation conditions of most optoelectronic devices and is potentially compatible with thermal vacuum deposition of polycrystalline thin films.

\section{Introduction}

Lead iodide perovskites have shown excellent photovoltaic (PV) as well as electroluminescent properties. ${ }^{[1,2]}$ In part due to the toxicity of $\mathrm{Pb}^{2+}$ ions, other metal halide perovskites are being investigated. Divalent tin is the most straightforward alternative to lead, considering their similar electronic configuration (group 14) and similar ionic radiuses. ${ }^{[3-34]}$ Furthermore, mixed $\mathrm{Sn}-\mathrm{Pb}$ iodide perovskites possess a lower bandgap than pure $\mathrm{Pb}$ and $\mathrm{Sn}$ ones, with applications in both single junction and tandem solar cells. ${ }^{[35]}$ One problem that arises with the use of $\mathrm{Sn}(\mathrm{II})$ is that it may be easily oxidized to $\mathrm{Sn}(\mathrm{IV})$. Two workarounds exist to this problem: (i) limiting the oxidation by using additives such as $\mathrm{SnF}_{2},{ }^{[8,11,12,33,36]}$ or (ii) exploring the properties of $\mathrm{Sn}(\mathrm{IV})$-based materials. ${ }^{[37-48]} \mathrm{A}_{2} \mathrm{~B}(\mathrm{IV}) \mathrm{X}_{6}$ compounds can be seen as a similar structure to the $\mathrm{AB}(\mathrm{II}) \mathrm{X}_{3}$ perovskite where every other $\mathrm{BX}_{6}$ octahedra is removed, and $\mathrm{B}$ is in +4 oxidation state to ensure charge neutrality (see Scheme 1).

These compounds are sometimes referred to as vacancy-ordered double perovskites, where the B-"vacancies" are described as virtual cations, also explaining why the stoichiometry of $\mathrm{A}_{2} \mathrm{BX}_{6}$ is often written as 2- $\square-1-6 . \mathrm{Cs}_{2} \mathrm{SnI}_{6}$ has been shown to be a degradation product of $\mathrm{CsSnI}_{3}$ upon air-exposure. ${ }^{[46]}$ Although this compound can be seen as a zero-dimensional structure due to the fact that adjacent $\mathrm{SnI}_{6}$ octahedra do not share any corners, their vicinity and consequent orbital overlap results in interesting optoelectronic properties for $\mathrm{PV}^{[46]}$ Mechanochemical synthesis via ball-milling or other techniques (e.g., hand grinding) provides 


\section{WILEY-VCH}

an ideal platform to form a wide variety of perovskites in stoichiometric and solvent-free conditions. ${ }^{[49,50,50-70]}$

Additionally, these compounds may later be used for thin film deposition by single-source thermal evaporation. ${ }^{[52]}$ The high number of recent publications indicate that mechanochemical synthesis is starting to be a common practice in a few research groups focusing on halide perovskites and related compounds, and we foresee that it will be a widespread approach in the near future. Surprisingly, given the interest on tin perovskites, we could only find two publications focusing on mechanochemical synthesis of such compounds. The first one is the seminal work of Stoumpos et al. ${ }^{[71]}$ where mechanochemical synthesis (grinding by hand with mortar and pestle) was found to yield non-pure perovskites with considerable amounts of unreacted precursors. The second reference is a recent work from Saski et al. ${ }^{[59]}$ where several 3D pure-tin mixed iodide-bromide perovskites were synthesized. To the best of our knowledge, no reports either on mixed $\mathrm{Sn}-\mathrm{Pb}$ (especially relevant for low bandgap applications as previously discussed) or on 0D iodide perovskites by mechanochemistry exist. Also, the only report of 3D iodide perovskites made by mechanochemical synthesis that we are aware of ${ }^{[59]}$ does not provide thermal stability or electrical conductivity characterization.

Hereafter, we have used ball-milling to synthesize the pure $\mathrm{Sn}$ and mixed $\mathrm{Sn}-\mathrm{Pb}$ iodide perovskites $\mathrm{CsSnI}_{3}, \mathrm{FASnI}_{3}, \mathrm{Cs}(\mathrm{PbSn}) \mathrm{I}_{3}$, and $\mathrm{FA}(\mathrm{PbSn}) \mathrm{I}_{3}$ as well as the $\mathrm{Sn}(\mathrm{IV})$-based vacancy-ordered perovskites $\mathrm{Cs}_{2} \mathrm{SnI}_{6}$ and $\mathrm{FA}_{2} \mathrm{SnI}_{6}\left(\mathrm{FA}=\right.$ formamidinium $\left.=\mathrm{HC}\left(\mathrm{NH}_{2}\right)_{2}{ }^{+}\right)$. The influence of $\mathrm{SnF}_{2}$ as additive in the synthesis is also investigated. The elemental, chemical and structural characteristics of the as-prepared compounds are investigated by X-ray diffraction (XRD) and X-ray photoelectron spectroscopy (XPS). Furthermore, the thermal stability is studied by means of differential thermal analysis and thermogravimetry (DTA/TG). The energy level diagram is estimated from optical characterization and ultraviolet photoelectron spectroscopy (UPS). In addition, the charge carrier mobility and lifetime of 3D 


\section{WILEY-VCH}

$\mathrm{Sn}(\mathrm{II})$-based perovskite and 0D Sn(IV)-based structure were investigated by time-resolved microwave conductivity (TRMC), revealing that the effective mobility is two orders of magnitude larger for 3D Sn(II)-based perovskites as compared to 0D $\mathrm{Sn}$ (IV)-based structures. These measurements show that the electronic properties of fully-inorganic Sn(II)-based perovskites are improved during synthesis by $\mathrm{Pb}$-mixing and addition of $\mathrm{SnF}_{2}$, which decreases the charge carrier conductivity caused by oxidation to Sn(IV).

\section{Results and Discussion}

Sn(II)- and Sn(IV)-based compounds were synthesized by dry ball-milling of stoichiometric mixtures of the different precursors (see experimental section for details). Figure 1 shows the XRD characterization of all metal iodide perovskites.

The X-ray diffractograms of $\mathrm{CsSnI}_{3}, \mathrm{FASnI}_{3}, \mathrm{Cs}_{2} \mathrm{SnI}_{6}$, and $\mathrm{FA}_{2} \mathrm{SnI}_{6}$ match very well with the corresponding reference bulk patterns. The mixed tin-lead compounds $\mathrm{Cs}(\mathrm{SnPb}) \mathrm{I}_{3}$ and $\mathrm{FA}(\mathrm{SnPb}) \mathrm{I}_{3}$ have XRD signals comparable to the pure tin compounds albeit slightly shifted to lower angles, as expected from a partial replacement of tin with a bigger cation such as lead. Accordingly, we also observe a shift to lower diffraction angles in FA-based compounds compared to Cs-based ones. These differences are more clearly observed in Figure S2, which shows the three more relevant regions of each diffractogram. The high phase purity and match with reference XRD patterns highlight the potential of mechanochemical synthesis to obtain high quality materials. As noted in the legend of Figure $1, \mathrm{CsSnI}_{3}$ and $\mathrm{Cs}(\mathrm{PbSn}) \mathrm{I}_{3}$ were formed in the presence of $\mathrm{SnF}_{2}$. This additive was found to be crucial in the synthesis of $\mathrm{CsSnI}_{3}$ (but not in the synthesis of $\mathrm{FASnI}_{3}$ ) to avoid the formation of $\mathrm{SnI}_{4}$, as revealed by thermal analyses (Figure 2, and Figures S3-S5). In particular, when comparing the DTA signal of $\mathrm{CsSnI}_{3}$ synthesized with and without $\mathrm{SnF}_{2}$ (Figure S3), an endothermic peak around 160 


\section{WILEY-VCH}

${ }^{\circ} \mathrm{C}$, ascribed to the melting of $\mathrm{SnI}_{4}$, is visible only in the case where no $\mathrm{SnF}_{2}$ is added. This peak is also absent in the case of $\mathrm{FASnI}_{3}$ even without additive (Figure 2).

Besides the effect of $\mathrm{SnF}_{2}$, all the samples were analyzed through DTA/TG to investigate their thermal stability (Fig. 2). $\mathrm{CsSnI}_{3}$ is stable up to $450{ }^{\circ} \mathrm{C}$, temperature at which it melts with the subsequent vaporization of $\mathrm{SnI}_{2}$ and $\mathrm{CsI} .{ }^{[14]}$ A very similar behavior was recorded for $\mathrm{Cs}(\mathrm{SnPb}) \mathrm{I}_{3}$ (Fig. S4). $\mathrm{Cs}_{2} \mathrm{SnI}_{6}$ seems less stable, decomposing at $\sim 320{ }^{\circ} \mathrm{C}$ due to $\mathrm{SnI}_{4}$ (b.p. $\sim$ $350{ }^{\circ} \mathrm{C}$ ) which is more volatile than $\mathrm{SnI}_{2}$ (b.p. $\sim 700{ }^{\circ} \mathrm{C}$ ). Indeed, the TG variation, equal to $53.6 \%$ and $47.0 \%$ in the first and second step, respectively, are consistent with the loss of $\mathrm{SnI}_{4}$ and CsI (whose melting point is reported in the DTA curve at $627{ }^{\circ} \mathrm{C}$ ). $\mathrm{FASnI}_{3}$ and $\mathrm{FA}(\mathrm{SnPb}) \mathrm{I}_{3}$ have considerable lower stability respect to the Cs-based counterparts because of the organic cation, which mainly drives the decomposition mechanism. ${ }^{[72]}$ Interestingly, $\mathrm{FA}_{2} \mathrm{SnI}_{6}$ is slightly more stable with respect to $\mathrm{FASnI}_{3}$ and $\mathrm{FA}(\mathrm{SnPb}) \mathrm{I}_{3}$, with the initial weight loss starting around $250{ }^{\circ} \mathrm{C}$ instead of $200{ }^{\circ} \mathrm{C}$. This might be due to a stronger interaction between FA molecules in $\mathrm{FA}_{2} \mathrm{SnI}_{6}$. However, the weight loss is much faster in this $\mathrm{Sn}(\mathrm{IV})$ compound, being completely vaporized at $400{ }^{\circ} \mathrm{C}$, consistent with the reaction: $\mathrm{FA}_{2} \mathrm{SnI}_{6} \rightarrow 2$ $\mathrm{FAI}+\mathrm{SnI}_{4}$. Similarly, the decomposition mechanism for $\mathrm{FASnI}_{3}$ and $\mathrm{FA}(\mathrm{SnPb}) \mathrm{I}_{3}$ could be summarized, respectively, as $\mathrm{FASnI}_{3} \rightarrow \mathrm{FAI}+\mathrm{SnI}_{2}$ and $\mathrm{FA}(\mathrm{SnPb}) \mathrm{I}_{3} \rightarrow \mathrm{FAI}+1 / 2 \mathrm{SnI}_{2}+1 / 2$ $\mathrm{PbI}_{2} \cdot{ }^{\left[{ }^{73]}\right.}$ However, their TG and DTA curves evidence a more complex mechanism involving the formation of several intermediates. The last weight losses in TG curves of $\mathrm{FASnI}_{3}$ and $\mathrm{FA}(\mathrm{SnPb}) \mathrm{I}_{3}$ start at $\sim 500{ }^{\circ} \mathrm{C}$, temperature at which $\mathrm{SnI}_{2}$ is released, as also observed in the inorganic Cs-based counterparts (Figure S4). This further confirms that Sn remains in +2 oxidation state in these hybrid perovskites without addition of $\mathrm{SnF}_{2}$.

All $\mathrm{Sn}(\mathrm{II})$ and $\mathrm{Sn}(\mathrm{IV})$ perovskites were further analyzed by high-resolution XPS, in order to gather quantitative information on their chemical composition (XPS spectra of all compounds are shown in Figure 3 and atomic percentages of relevant elements are given in Table 1). 


\section{WILEY-VCH}

Carbon $\mathrm{C}$ 1s spectra of all samples show a peak at low binding energy (BE) which is ascribed to $\mathrm{C}-\mathrm{C}$ bonds of adventitious carbon originating from exposure to organic volatile compounds in air. This peak is fixed to $\mathrm{BE}=284.5 \mathrm{eV}$ for energy calibration, as standard practice. FAbased samples show a second peak at $\mathrm{BE}=287.9+/-0.2 \mathrm{eV}$ assigned to the carbon atom in formamidinium cations. Although not shown in Figure 3, $\mathrm{CsSnI}_{3}$ and $\mathrm{Cs}(\mathrm{SnPb}) \mathrm{I}_{3}$ samples exhibit an additional peak at $\mathrm{BE}=684.0 \mathrm{eV}$ corresponding to the $\mathrm{F}$ 1s orbital from $\mathrm{SnF}_{2}$ (see Figure S6). Quantitative elemental analysis can be derived from these high-resolution spectra, after correcting for $\mathrm{SnF}_{2}$ contribution and considering only the highest energy component of $\mathrm{C}$ 1s. Atomic percentages of all relevant elements are given in Table 1.

Several observations can be made from Table 1 . First of all, $\mathrm{FA}_{2} \mathrm{SnI}_{6}$ seems highly degraded as only a very low amount of tin is detected. This suggests that this compound is severely affected by X-ray radiation and ultrahigh vacuum, leading most likely to the formation and subsequent loss of $\mathrm{SnI}_{4}$. For all the other compounds we note that the A:B ratios (where $\mathrm{A}$ is either $\mathrm{Cs}$ or $\mathrm{FA}$ and $\mathrm{B}$ is either $\mathrm{Sn}$ or $\mathrm{SnPb}$ ) are very close to the expected 1:1 or 2:1 ratios, further confirming the material purity already observed by XRD. The same is true for the $\mathrm{Sn}: \mathrm{Pb}$ ratios, which are close to $1: 1$ in both mixed tin-lead perovskites. The $\mathrm{C}: \mathrm{N}$ ratios in FAbased samples are close to the expected 1:2 ratio for FA cations, confirming the assignment of the high-BE component of $\mathrm{C} 1 \mathrm{~s}$ spectra to FA and, importantly, suggesting that FA is not degraded during mechanochemical synthesis. This is not obvious a priori, as FAI is known to give different degradation byproducts, such as $\mathrm{HCN}$ or others, which could be volatile and hence alter the C:N ratio in the sample. ${ }^{[74]}$ Nonetheless, we note that in all samples the measured iodine concentration is lower than expected. In regards to this, it should be noted that we also observe oxygen (see Figure S7), which is likely due to oxidation upon air exposure prior to analysis. Indeed, although the synthesis is carried out under nitrogen (see experimental section for details), the samples are exposed to air for a short time before characterization. As photoelectron spectroscopies are surface-sensitive techniques (depth of 


\section{WILEY-VCH}

analysis is typically few nanometers), even a small superficial oxidation will have a high impact on XPS results. In other words, it is unlikely that a significant formation of $\mathrm{SnO}_{\mathrm{x}}$ affects the bulk of the perovskites here, as these species do not appear in the XRD signal (Figure 1). Furthermore, based on literature, the formation of significant $\mathrm{SnO}_{\mathrm{x}}$ in the bulk from air exposure is a process that typically takes several days or weeks. ${ }^{[46]} \mathrm{A}$ closer look at XPS spectra (Figure 3) allows to further discuss the oxidation states and chemical environments of the different elements in all samples. In the case of Cs-based samples, the Cs $3 \mathrm{~d}$ spectra show a doublet with $\mathrm{Cs} 3 \mathrm{~d}_{5 / 2}$ peak located at $\mathrm{BE}=724.0+/-0.3 \mathrm{eV}$ as well as $\mathrm{I} 3 \mathrm{~d}$ spectra with $\mathrm{I} 3 \mathrm{~d}_{5 / 2}$ at $\mathrm{BE}=618.7 \mathrm{eV}+/-0.2 \mathrm{eV}$. These values are consistent with $\mathrm{Cs}(+1)$ and I(-1) oxidation states expected for inorganic iodide perovskites. ${ }^{[75]}$ The Sn $3 \mathrm{~d}$ spectra of $\mathrm{CsSnI}_{3}$ and $\mathrm{Cs}(\mathrm{SnPb}) \mathrm{I}_{3}$ show two clear components (two doublets) ascribed to the addition of $\mathrm{SnF}_{2}$ in these samples, while $\mathrm{Cs}_{2} \mathrm{SnI}_{6}$ shows only one component, as expected. Comparing the BE values of $\mathrm{Sn}$ (II) and $\mathrm{Sn}(\mathrm{IV})$ reported in literature, it seems unlikely to easily distinguish them, as these values largely overlap. ${ }^{[76]}$ In the case of $\mathrm{Cs}(\mathrm{SnPb}) \mathrm{I}_{3}$ we note that $\mathrm{Pb} 4 \mathrm{f}$ spectra are asymmetric with a low-BE component whose origin could not be clearly elucidated. Importantly, no metallic lead (or tin) was observed in any of the samples (the $\mathrm{Sn} 3 \mathrm{~d}$ and $\mathrm{Pb} 4 \mathrm{f}$ peak positions for metallic tin and lead are indicated by dashed lines in Figure 2), which could otherwise have a detrimental effect on the perovskite optoelectronic properties. ${ }^{[77-79]}$ In the case of FA-based samples, the peak at $\mathrm{BE}=287.9+/-0.2 \mathrm{eV}$ is assigned to the carbon atom of FA cations. Accordingly, the $\mathrm{N}$ 1s peak is at $\mathrm{BE}=400.2+/-0.1 \mathrm{eV}$, corresponding to the $\mathrm{N}$ atoms of FA. Interestingly, $\mathrm{FASnI}_{3}$ sample shows a second peak at lower BE which may be

ascribed to deprotonated amines in FA (noted in the graph as $\mathrm{C}-\mathrm{NH}_{2}{ }^{0}$ ) ${ }^{[80,81]}$ Here, the deprotonation of FA is concomitant to the formation of different iodine species, as evidenced by the I $3 \mathrm{~d}$ spectra, which only in the case of $\mathrm{FASnI}_{3}$ shows two different components. It is possible that a partial proton transfer from FA to $\mathrm{I}^{-}$occurs. Nonetheless, the complexity of iodine chemistry in hybrid perovskites complicate the identification of the exact species 


\section{WILEY-VCH}

formed here. ${ }^{[82]}$ Sn $3 d$ spectra of the three FA-based compounds show a main $\mathrm{Sn} 3 \mathrm{~d}_{5 / 2}$ peak centered at $\mathrm{BE}=487.1+/-0.1 \mathrm{eV}$, consistent both with $\mathrm{Sn}$ (II) and $\mathrm{Sn}(\mathrm{IV})$ iodide perovskites. ${ }^{[30]}$ A small component at lower BE appears in the Sn 3d spectrum in the case of $\mathrm{FA}(\mathrm{SnPb}) \mathrm{I}_{3}$ sample, somehow similar to the lead signal in $\mathrm{Cs}(\mathrm{SnPb}) \mathrm{I}_{3}$. This low $\mathrm{BE}$ component might be due to oxidation as previously discussed. In summary, aside from $\mathrm{FA}_{2} \mathrm{SnI}_{6}$ that is degraded under characterization, XPS spectra confirm overall the formation of the entire series of compounds, with signals that match with the expected spectra of the different perovskites (and the corresponding signal for $\mathrm{SnF}_{2}$ in the $\mathrm{CsSnI}_{3}$ and $\mathrm{Cs}(\mathrm{SnPb}) \mathrm{I}_{3}$ samples).

Optical characterization (diffuse reflectance and photoluminescence) as well as ultraviolet photoelectron spectroscopy (UPS) were performed to estimate the energetic positions of the valence band, Fermi level and conduction band of these materials (Figure 4).

All compounds have an absorption onset in the near-infrared (NIR) region, suited for single junction solar cells as well as rear absorber in perovskite-perovskite tandem devices. All Sn(II)-based compounds have clear Stokes-shifted photoluminescence at room temperature (Figure 4), which make them potentially interesting also for near-infrared light-emitting diodes. The UPS secondary electron cut-off (Figure 4, middle column) and onset (right column) allow us to determine the work function and the energy difference between the Fermi level and the top of the valence band, respectively. Combining this information, we are able to estimate the characteristic energy levels as presented at the bottom of Figure 4. The addition of lead to Sn(II)-based perovskites results in deeper energy levels as compared to the pure-tin counterparts, which is consistent with the literature. ${ }^{[83]}$ Furthermore, a red-shift in PL is clearly observed from pure-tin $\mathrm{FASnI}_{3}$ to mixed tin-lead $\mathrm{FA}(\mathrm{SnPb}) \mathrm{I}_{3}$. Such behavior has also been noted by others, where mixed tin-lead perovskites were found to have a lower bandgap than both pure-tin and pure-lead compositions. ${ }^{[84]}$ Interestingly we do not observe this phenomenon in inorganic Cs-based perovskites. The apparent p-type doping in $\mathrm{FASnI}_{3}$ may 


\section{WILEY-VCH}

be ascribed to a partial oxidation of $\mathrm{Sn}(\mathrm{II})$ to $\mathrm{Sn}(\mathrm{IV}) .{ }^{[85]}$ On the other hand, mixed $\mathrm{FA}(\mathrm{SnPb}) \mathrm{I}_{3}$ seems to be rather n-type. The origin of this effect is not fully elucidated. However, we already noted in the discussion of XPS data (Figure 3, blue spectra) that tin appeared to be slightly reduced, which might explain the n-type character observed here. Again, these effects do not seem to be significant for inorganic Cs-based compounds, as both appear rather intrinsic semiconductors. It must be noted though that these perovskites were formed with addition of $\mathrm{SnF}_{2}$. We therefore infer that $\mathrm{SnF}_{2}$ helps maintaining the intrinsic nature of the semiconductor by preventing oxidation of tin. For Sn(IV) compounds, we clearly see a difference from the valence band maximum to the Fermi level (UPS onset, right column) of $1.5 \mathrm{eV}$, close to the reported bandgap for the same material. ${ }^{[86]}$ Unfortunately, we cannot determine the optical bandgap, due to the smooth absorption onset and lack of photoluminescence. As it cannot be lower than $1.5 \mathrm{eV}$, we take this as the bandgap (it seems a reasonable assumption considering that the sample is clearly black; see Figure S8). These observations mean that these materials are heavily n-doped. Again, this conclusion is in agreement with literature, where $\mathrm{Cs}_{2} \mathrm{SnI}_{6}$ has been reported by several groups to be intrinsically n-type. ${ }^{[45]}$

Eventually, we studied the mobility and lifetime of charge carriers by pulse-radiolysis timeresolved microwave conductivity (PR-TRMC). In this technique, materials are ionized with a high energy electron pulse and, subsequently, the change in conductivity is probed with $\mathrm{GHz}$ microwaves. If irradiation leads to mobile charge carriers, these will absorb part of the microwave power, decreasing the microwave power reflected by the cell. This decrease in microwave power is directly related to the change in conductivity and ultimately to the mobility of charge carriers. ${ }^{[87]}$ We note that in most samples, measurements were not possible due to high or even complete absorption of the microwaves without irradiation. This is indicative of a considerable dark conductivity that hinders the detection of changes in conductivity upon irradiation. This behaviour matches with the UPS measurements, where we 


\section{WILEY-VCH}

observe that most samples are doped either with a p-type character, most likely caused by oxidation of $\mathrm{Sn}^{2+}$ to $\mathrm{Sn}^{4+}$, or a n-type character. It has been shown in literature that presence of low concentrations of dark charge carriers has a strong detrimental effect on the electronic properties. ${ }^{[8,11,12,33,36]}$ In fact, we are able to observe change of reflection (not quantifiable) that is very short-lived $(<5 \mathrm{~ns})$, which indicates that the generated charge carriers recombine or are trapped within the time resolution of the PR-TRMC experiment (see Figure S9). Nevertheless, we were able to obtain meaningful results on two compounds: a 3D Sn(II)based compound $\left(\mathrm{Cs}(\mathrm{SnPb}) \mathrm{I}_{3}\right)$ and a $0 \mathrm{D} \mathrm{Sn}(\mathrm{IV})$-based compound $\left(\mathrm{FA}_{2} \mathrm{SnI}_{6}\right)$, which are hereafter simply referred to as 3D and $0 \mathrm{D}$ samples (Figure $5 \mathrm{a}$ ). The fact that we can measure these samples matches with the UPS measurements, where $\mathrm{Cs}(\mathrm{SnPb}) \mathrm{I}_{3}$ seems to be an intrinsic semiconductor. This intrinsic character is most likely achieved during synthesis. Where decreasing tin content with lead and adding $\mathrm{SnF}_{2}$ suppresses $\mathrm{Sn}^{2+}$ oxidation to $\mathrm{Sn}^{4+}$ and as a result decreases the concentration of dark charge carriers. This is also in line with reported improved stabilities of tin based perovskites when also lead cations are present. ${ }^{[88]}$ As can be seen in Figure 5a, the 3D sample shows a charge carrier mobility is 2 orders of magnitude higher compared to the $0 \mathrm{D}$ sample $\left(0.2\right.$ and $0.004 \mathrm{~cm}^{2} / \mathrm{Vs}$, respectively). This is not surprising if we consider that the higher dimensionality of the 3D sample leads to a higher overlap of molecular orbitals. In both cases, the mobility was not found to significantly change when cooling from RT to $173 \mathrm{~K}$. This indicates that the charge carrier mobility is not dominated by lattice scattering, but may be controlled by defects. The mobility of the 3D sample is of the same order of magnitude as for 3D lead-based perovskite samples prepared without the use of solvents, ${ }^{[89]}$ while it is one to two orders of magnitude lower than $3 \mathrm{D}$ leadbased perovskites prepared by precipitation or single crystals, respectively. ${ }^{[89,90]}$ This points out that dry mechanochemical synthesis as performed here might lead to a higher density of defects as opposed to solution-processing. Nonetheless, we believe that the synthesis may be optimized, for example by reducing the grinding time, which in this case was 5 hours. Such a 


\section{WILEY-VCH}

long time is probably unnecessary to yield phase pure perovskites, and reducing it will likely limit detrimental effects of prolonged grinding (i.e. tin oxidation). The time-resolved conductivity (Figure 5b) of the 3D sample shows a fast-initial decay followed by a long-tail that does not decay to zero, even at very long times. Also, the maximum change in conductivity increases with the initial concentration of charge carriers (increase pulse length; see Figure $\mathrm{S} 10$ ). This behavior is similar to the observed for $3 \mathrm{D} \mathrm{MAPbX}_{3}$ samples, ${ }^{[89]}$ and is

attributed to second order recombination with a limited concentration of trap states. ${ }^{[89]}$ The fast-initial decay is caused by trapping of one of the charges and the long tail signal comes from the remaining free charges. ${ }^{[89,90]}$ As for the mobility, the carrier lifetime seems almost unaffected by temperature (see Figure S11), indicating that the decay is still dominated by the recombination with a similar concentrations of the trap states as at room temperature. In the case of the $0 \mathrm{D}$ sample, the conductivity signal is very low and decays in less than $50 \mathrm{~ns}$ (Figure 5b). However, we observe a slight conductivity increase at low temperatures which may be related to less thermal vibration of the lattice (see Figure S12).

\section{Conclusion}

In conclusion we have been able to synthesize hybrid and inorganic pure-tin and mixed tinlead iodide perovskites and vacancy ordered perovskites with excellent phase purity as revealed by XRD. Detailed thermal stability studies were carried out revealing that all compounds are be stable up to $200{ }^{\circ} \mathrm{C}$, which is compatible with common operational conditions in optoelectronic devices. Inorganic perovskites based on $\mathrm{Sn}$ (II) were found to be stable beyond $400^{\circ} \mathrm{C}$, making them good candidates for single source thermal deposition in thin films. Indeed, these compounds show a narrow bandgap suited for photovoltaics and near-IR LEDs. The charge carrier mobility was found to be rather low which could be due to oxidation during the long ball-milling mechanochemical synthesis. However, we demonstrated that the dark carrier conductivity in inorganic 3D Sn(II)-based compounds can 


\section{WILEY-VCH}

be improved by addition of $\mathrm{Pb}(\mathrm{II})$ and/or $\mathrm{SnF}_{2}$ during synthesis. Ongoing work is focused on optimizing the preparation conditions, especially reducing the grinding time to an ideal duration that will ensure a complete synthesis while avoiding possible detrimental effects.

\section{Supporting Information}

Supporting Information is available from the Wiley Online Library or from the author.

\section{Acknowledgements}

The research leading to these results has received funding from the European Union Programme for Research and Innovation Horizon 2020 (2014-2020) under the Marie Skddowska -Curie Grant Agreement PerovSAMs No. 747599, and project INFORM (grant 675867), the Spanish Ministry of Economy and Competitiveness (MINECO) via the Unidad de Excelencia María de Maeztu MDM-2015-0538, MAT2017-88821-R and PCIN-2015-255, and the Generalitat Valenciana (Prometeo/2016/135 and GRISOLIAP/2017/089). H. J. B. acknowledges the support of ERA NET PCIN-2017-014. M. S. thanks the MINECO for his RyC contract. The research leading to these results in the Delft University of Technology has received funding from the European Research Council Horizon 2020 ERC Grant Agreement no. 648433 .

Received: ((will be filled in by the editorial staff))

Revised: ((will be filled in by the editorial staff)) Published online: ((will be filled in by the editorial staff))

References

[1] B. Dänekamp, N. Droseros, F. Palazon, M. Sessolo, N. Banerji, H. J. Bolink, ACS Appl. Mater. Interfaces 2018, acsami.8b13100.

[2] Q. A. Akkerman, L. Martínez-Sarti, L. Goldoni, M. Imran, D. Baranov, H. J. Bolink, F. Palazon, L. Manna, Chem. Mater. 2018, 30, 6915. 


\section{WILEY-VCH}

[3] D. B. Mitzi, C. A. Feild, Z. Schlesinger, R. B. Laibowitz, J. Solid State Chem. 1995, $114,159$.

[4] N. K. Noel, S. D. Stranks, A. Abate, C. Wehrenfennig, S. Guarnera, A. A. Haghighirad, A. Sadhanala, G. E. Eperon, S. K. Pathak, M. B. Johnston, A. Petrozza, L. M. Herz, H. J. Snaith, Energy Environ. Sci. 2014, 7, 3061.

[5] Z. Zhao, F. Gu, Y. Li, W. Sun, S. Ye, H. Rao, Z. Liu, 2017, 1700204.

[6] J. Jiang, C. K. Onwudinanti, R. A. Hatton, P. A. Bobbert, S. Tao, J. Phys. Chem. C 2018, 122,17660 .

[7] Z. Chen, J. J. Wang, Y. Ren, C. Yu, K. Shum, Z. Chen, J. J. Wang, Y. Ren, C. Yu, K. Shum, 2012, 093901.

[8] M. H. Kumar, S. Dharani, W. L. Leong, P. P. Boix, R. R. Prabhakar, T. Baikie, C. Shi, H. Ding, R. Ramesh, M. Asta, M. Graetzel, S. G. Mhaisalkar, N. Mathews, Adv. Mater 2014, 26, 7122 .

[9] A. Wang, Y. Guo, F. Muhammad, Z. Deng, Chem. Mater. 2017, $29,6493$.

[10] N. Wang, Y. Zhou, M. G. Ju, H. F. Garces, T. Ding, S. Pang, X. C. Zeng, N. P. Padture, X. W.Sun, Adv, Energy Mater. 2016, 6, 1.

[11] S. Gupta, T. Bendikov, G. Hodes, D. Cahen, ACS Energy Lett. 2016, 1, 1028.

[12] A. G. Kontos, A. Kaltzoglou, E. Siranidi, D. Palles, G. K. Angeli, M. K. Arfanis, V. Psycharis, Y. S. Raptis, E. I. Kamitsos, P. N. Trikalitis, C. C. Stoumpos, M. G. Kanatzidis, P. Falaras, Inorg. Chem. 2017, 56, 84.

[13] P. Xu, S. Chen, H. J. Xiang, X. G. Gong, S. H. Wei, Chem. Mater. 2014, 26, 6068.

[14] I. Chung, J. H. Song, J. Im, J. Androulakis, C. D. Malliakas, H. Li, A. J. Freeman, J. T. Kenney, M. G. Kanatzidis, J. Am. Chem. Soc. 2012, 134, 8579.

[15] F. Hao, C. C. Stoumpos, D. H. Cao, R. P. H. Chang, M. G. Kanatzidis, Nat. Photonics 2014.

[16] L. Y. Huang, W. R. L. Lambrecht, Phys. Rev. B - Condens. Matter Mater. Phys. 2013, 


\section{WILEY-VCH}

$88,1$.

[17] W. Li, J. Li, J. Li, J. Fan, Y. Mai, L. Wang, J. Mater. Chem. A 2016, 4, 17104.

[18] D. Sabba, H. K. Mulmudi, R. R. Prabhakar, T. Krishnamoorthy, T. Baikie, P. P. Boix, S. Mhaisalkar, N. Mathews, J. Phys. Chem. C 2015, 119, 1763.

[19] C. Grote, R. F. Berger, J. Phys. Chem. C 2015, 119, 22832.

[20] G. Fisher, 1973, 14, 308.

[21] C. G. Ma, V. Krasnenko, M. G. Brik, J. Phys. Chem. Solids 2018, 115, 289.

[22] E. L. Da Silva, J. M. Skelton, S. C. Parker, A. Walsh, Phys. Rev. B - Condens. Matter Mater. Phys. 2015, 91, 1.

[23] K. P. Marshall, M. Walker, R. I. Walton, R. A. Hatton, J. Mater. Chem. A 2017, 5, 21836.

[24] K. P. Marshall, M. Walker, R. I. Walton, R. A. Hatton, Nat. Energy 2016, 1, 1.

[25] Y. K. Jung, J. H. Lee, A. Walsh, A. Soon, Chem. Mater. 2017, 29, 3181.

[26] F. Hao, C. C. Stoumpos, R. P. H. Chang, M. G. Kanatzidis, 2014.

[27] G. Thiele, B. R. Serr, Zeitschrift fur Krist. - New Cryst. Struct. 1995, 210, 64.

[28] K. P. Marshall, S. Tao, M. Walker, D. S. Cook, J. Lloyd-Hughes, S. Varagnolo, A. Wijesekara, D. Walker, R. I. Walton, R. A. Hatton, Mater. Chem. Front. 2018, 2, 1515.

[29] F. Wang, J. Ma, F. Xie, L. Li, J. Chen, J. Fan, N. Zhao, 2016, 3417.

[30] T. Song, T. Yokoyama, C. C. Stoumpos, J. Logsdon, D. H. Cao, M. R. Wasielewski, S. Aramaki, M. G. Kanatzidis, 2017.

[31] F. Chiarella, A. Zappettini, F. Licci, I. Borriello, G. Cantele, D. Ninno, A. Cassinese, R. Vaglio, Phys. Rev. B - Condens. Matter Mater. Phys. 2008, 77, 1.

[32] W. Liao, D. Zhao, Y. Yu, C. R. Grice, C. Wang, A. J. Cimaroli, P. Schulz, W. Meng, K. Zhu, R. Xiong, Y. Yan, 2016, 9333.

[33] S. J. Lee, S. S. Shin, Y. C. Kim, D. Kim, T. K. Ahn, J. H. Noh, J. Seo, S. Il Seok, J. Am. Chem. Soc. 2016, 138, 3974. 


\section{WILEY-VCH}

[34] S. Shao, J. Liu, G. Portale, H. H. Fang, G. R. Blake, G. H. ten Brink, L. J. A. Koster, M. A. Loi, Adv. Energy Mater. 2018, 8 .

[35] D. Zhao, C. Chen, C. Wang, M. M. Junda, Z. Song, C. R. Grice, Y. Yu, C. Li, B. Subedi, N. J. Podraza, X. Zhao, G. Fang, R. Xiong, K. Zhu, Y. Yan, Nat. Energy 2018, $3,1093$.

[36] I. Chung, B. Lee, J. He, R. P. H. Chang, M. G. Kanatzidis, Nature 2012, 485, 486.

[37] B. Lee, C. C. Stoumpos, N. Zhou, F. Hao, C. Malliakas, C. Y. Yeh, T. J. Marks, M. G. Kanatzidis, R. P. H. Chang, J. Am. Chem. Soc. 2014, 136, 15379.

[38] Z. Xiao, H. Lei, X. Zhang, Y. Zhou, H. Hosono, T. Kamiya, Bull. Chem. Soc. Jpn. $2015,88,1250$.

[39] A. Kaltzoglou, M. Antoniadou, A. G. Kontos, C. C. Stoumpos, D. Perganti, E. Siranidi, V. Raptis, K. Trohidou, V. Psycharis, M. G. Kanatzidis, P. Falaras, J. Phys. Chem. C 2016, 120,11777 .

[40] A. Kaltzoglou, M. Antoniadou, D. Perganti, E. Siranidi, V. Raptis, K. Trohidou, V. Psycharis, A. G. Kontos, P. Falaras, Electrochim. Acta 2015, 184, 466.

[41] B. Saparov, J. P. Sun, W. Meng, Z. Xiao, H. S. Duan, O. Gunawan, D. Shin, I. G. Hill, Y. Yan, D. B. Mitzi, Chem. Mater. 2016, 28, 2315.

[42] Z. Tan, J. Li, C. Zhang, Z. Li, Q. Hu, Z. Xiao, T. Kamiya, H. Hosono, G. Niu, E. Lifshitz, Y. Cheng, J. Tang, Adv. Funct. Mater. 2018, 1801131, doi: $10.1002 /$ adfm.201801131.

[43] A. E. Maughan, A. M. Ganose, A. M. Candia, J. T. Granger, D. O. Scanlon, J. R. Neilson, Chem. Mater. 2018, 30, 472.

[44] A. E. Maughan, A. M. Ganose, M. A. Almaker, D. O. Scanlon, J. R. Neilson, Chem. Mater. 2018, 30, 3909.

[45] Z. Xiao, Y. Zhou, H. Hosono, T. Kamiya, Phys. Chem. Chem. Phys. 2015, 17, 18900.

[46] X. Qiu, B. Cao, S. Yuan, X. Chen, Z. Qiu, Y. Jiang, Q. Ye, H. Wang, H. Zeng, J. Liu, This article is protected by copyright. All rights reserved 


\section{WILEY-VCH}

M. G. Kanatzidis, Sol. Energy Mater. Sol. Cells 2017, 159, 227.

[47] J. C. R. Ke, D. J. Lewis, A. S. Walton, B. F. Spencer, P. O’Brien, A. G. Thomas, W. R. Flavell, J. Mater. Chem. A 2018, 6, 11205.

[48] B. Lee, A. Krenselewski, S. Il Baik, D. N. Seidman, R. P. H. Chang, Sustain. Energy Fuels 2017, 1, 710 .

[49] O. Y. Posudievsky, N. V. Konoshchuk, V. L. Karbivskyy, O. P. Boiko, V. G. Koshechko, V. D. Pokhodenko, Theor. Exp. Chem. 2017, 53, 235.

[50] D. Prochowicz, P. Yadav, M. Saliba, D. J. Kubicki, M. M. Tavakoli, S. M. Zakeeruddin, J. Lewiŕski, L. Emsley, M. Grätzel, Nano Energy 2018, 49, 523.

[51] A. Karmakar, A. M. Askar, G. M. Bernard, V. V. Terskikh, M. Ha, S. Patel, K. Shankar, V. K. Michaelis, Chem. Mater. 2018, 30, 2309.

[52] Y. El Ajjouri, F. Palazon, M. Sessolo, H. J. Bolink, Chem. Mater. 2018, 30, 7423.

[53] D. J. Kubicki, D. Prochowicz, A. Hofstetter, S. M. Zakeeruddin, M. Grätzel, L. Emsley, J. Am. Chem. Soc. 2018, 140, 7232.

[54] Z. Y. Zhu, Q. Q. Yang, L. F. Gao, L. Zhang, A. Y. Shi, C. L. Sun, Q. Wang, H. L. Zhang, J. Phys. Chem. Lett. 2017, 8, 1610.

[55] D. Prochowicz, M. Franckeviđ̛̌us, A. M. Ciekak, S. M. Zakeeruddin, M. Grätzel, J. Lewirski, J. Mater. Chem. A 2015, 3, 20772.

[56] A. D. Jodlowski, A. Yépez, R. Luque, L. Camacho, G. de Miguel, Angew. Chemie - Int. Ed. 2016, 55, 14972.

[57] L. Protesescu, S. Yakunin, O. Nazarenko, D. N. Dirin, M. V. Kovalenko, ACS Appl. Nano Mater. 2018, 1, 1300.

[58] D. J. Kubicki, D. Prochowicz, A. Hofstetter, S. M. Zakeeruddin, M. Grätzel, L. Emsley, J. Am. Chem. Soc. 2017, 139, 14173.

[59] M. Saski, D. Prochowicz, W. Marynowski, J. Lewinski, Eur. J. Inorg. Chem. 2019, 3.

[60] Y. E. El Ajjouri, V. S. S. S. Chirvony, M. Sessolo, Y. El Ajjouri, V. S. Chirvony, M. 


\section{WILEY-VCH}

Sessolo, F. Palazon, H. J. Bolink, RSC Adv. 2018, 8, 41548.

[61] J. V. Miliç J. H. Im, D. J. Kubicki, A. Ummadisingu, J. Y. Seo, Y. Li, M. A. RuizPreciado, M. I. Dar, S. M. Zakeeruddin, L. Emsley, M. Grätzel, Adv. Energy Mater. 2019, 1900284, 1.

[62] A. Karmakar, M. S. Dodd, X. Zhang, M. S. Oakley, M. Klobukowski, V. K. Michaelis, Chem. Commun. 2019, 55, 5079.

[63] Y. El Ajjouri, V. S. Chirvony, N. Vassilyeva, M. Sessolo, F. Palazon, H. J. Bolink, J. Mater. Chem. C 2019.

[64] J. Breternitz, S. Levcenko, H. Hempel, G. Gurieva, A. Franz, A. Hoser, S. Schorr, J. Phys. Energy 2018, 1, 25003.

[65] O. Y. Posudievsky, N. V. Konoshchuk, A. G. Shkavro, V. L. Karbivskiy, V. G. Koshechko, V. D. Pokhodenko, ACS Appl. Nano Mater. 2018, 1, 4145.

[66] S. Yun, A. Kirakosyan, S. G. Yoon, J. Choi, ACS Sustain. Chem. Eng. 2018, 6, 3733.

[67] M. Wilke, N. Casati, Chem. - A Eur. J. 2018.

[68] D. Prochowicz, P. Yadav, M. Saliba, M. Saski, S. M. Zakeeruddin, J. Lewiŕski, M. Grätzel, Sustain. Energy Fuels 2017, 1.

[69] P. Pal, S. Saha, A. Banik, A. Sarkar, K. Biswas, Chem. - A Eur. J. 2018, 24, 1811.

[70] A. M. Askar, A. Karmakar, G. M. Bernard, M. Ha, V. V. Terskikh, B. D. Wiltshire, S. Patel, J.Fleet, K. Shankar, V. K. Michaelis, J. Phys. Chem. Lett. 2018, 9, 2671.

[71] C. C. Stoumpos, C. D. Malliakas, M. G. Kanatzidis, Inorg. Chem. 2013, 52, 9019.

[72] T. Leijtens, R. Prasanna, A. Gold-Parker, M. F. Toney, M. D. McGehee, ACS Energy Lett. 2017, 2, 2159.

[73] Y. Dang, Y. Zhou, X. Liu, D. Ju, S. Xia, H. Xia, X. Tao, Angew. Chemie - Int. Ed. 2016, $55,3447$.

[74] I. Lignos, L. Protesescu, D. B. Emiroglu, R. MacEiczyk, S. Schneider, M. V. Kovalenko, A. J. DeMello, Nano Lett. 2018, 18, 1246. 


\section{WILEY-VCH}

[75] K. Wang, Z. Jin, L. Liang, H. Bian, D. Bai, H. Wang, J. Zhang, Q. Wang, L. Shengzhong, Nat. Commun. 2018, 9, 1.

[76] L. Jie, X. Chao, J. Non. Cryst. Solids 1990, 119, 37.

[77] G. Sadoughi, D. E. Starr, E. Handick, S. D. Stranks, M. Gorgoi, R. G. Wilks, M. Bär, H. J. Snaith, ACS Appl. Mater. Interfaces 2015, 7, 13440.

[78] H. Cho, S. H. Jeong, M. H. Park, Y. H. Kim, C. Wolf, C. L. Lee, J. H. Heo, A. Sadhanala, N. S. Myoung, S. Yoo, S. H. Im, R. H. Friend, T. W. Lee, Science (80-. ). $\mathbf{2 0 1 5}, 350,1222$.

[79] W. Zhang, S. Pathak, N. Sakai, T. Stergiopoulos, P. K. Nayak, N. K. Noel, A. A. Haghighirad, V. M. Burlakov, D. W. Dequilettes, A. Sadhanala, W. Li, L. Wang, D. S. Ginger, R. H. Friend, H. J. Snaith, Nat. Commun. 2015, 6, 1.

[80] A. Calloni, A. Abate, G. Bussetti, G. Berti, R. Yivlialin, F. Ciccacci, L. Duò, J. Phys. Chem. C 2015, 119, 21329.

[81] G. Abdelmageed, L. Jewell, K. Hellier, L. Seymour, B. Luo, F. Bridges, J. Z. Zhang, S. Carter, Appl. Phys. Lett. 2016, 109, 0.

[82] D. Meggiolaro, S. G. Motti, E. Mosconi, A. J. Barker, J. Ball, C. Andrea Riccardo Perini, F. Deschler, A. Petrozza, F. De Angelis, Energy Environ. Sci. 2018, 11, 702.

[83] W. Ke, C. C. Stoumpos, M. G. Kanatzidis, Adv. Mater. 2018, 1803230.

[84] D. Zhao, Y. Yu, C. Wang, W. Liao, N. Shrestha, C. R. Grice, A. J. Cimaroli, L. Guan, R. J. Ellingson, K. Zhu, X. Zhao, R. G. Xiong, Y. Yan, Nat. Energy 2017, 2, 1.

[85] S. J. Lee, S. S. Shin, J. Im, T. K. Ahn, J. H. Noh, N. J. Jeon, S. Il Seok, J. Seo, ACS Energy Lett. 2018, 3, 46.

[86] H. O. Shin, B. M. Kim, T. Jang, K. M. Kim, D. H. Roh, J. S. Nam, J. S. Kim, U. Y. Kim, B. Lee, Y. Pang, T. H. Kwon, Adv. Energy Mater. 2019, 9, 1.

[87] J. Warman, M. De Haas, G. Dicker, F. Grozema, Chem. Mater 2004, 4600.

[88] T. Leijtens, R. Prasanna, K. A. Bush, G. E. Eperon, J. A. Raiford, A. Gold-Parker, E. J. 


\section{WILEY-VCH}

Wolf, S. A. Swifter, C. C. Boyd, H. P. Wang, M. F. Toney, S. F. Bent, M. D. McGehee, Sustain. Energy Fuels 2018, 2, 2450.

[89] M. C. Gélvez-Rueda, D. H. Cao, S. Patwardhan, N. Renaud, C. C. Stoumpos, G. C.

Schatz, J. T. Hupp, O. K. Farha, T. J. Savenije, M. G. Kanatzidis, F. C. Grozema, J.

Phys. Chem. C 2016, 120, 16577.

[90] M. C. Gélvez-Rueda, N. Renaud, F. C. Grozema, J. Phys. Chem. C 2017, 121, 23392.

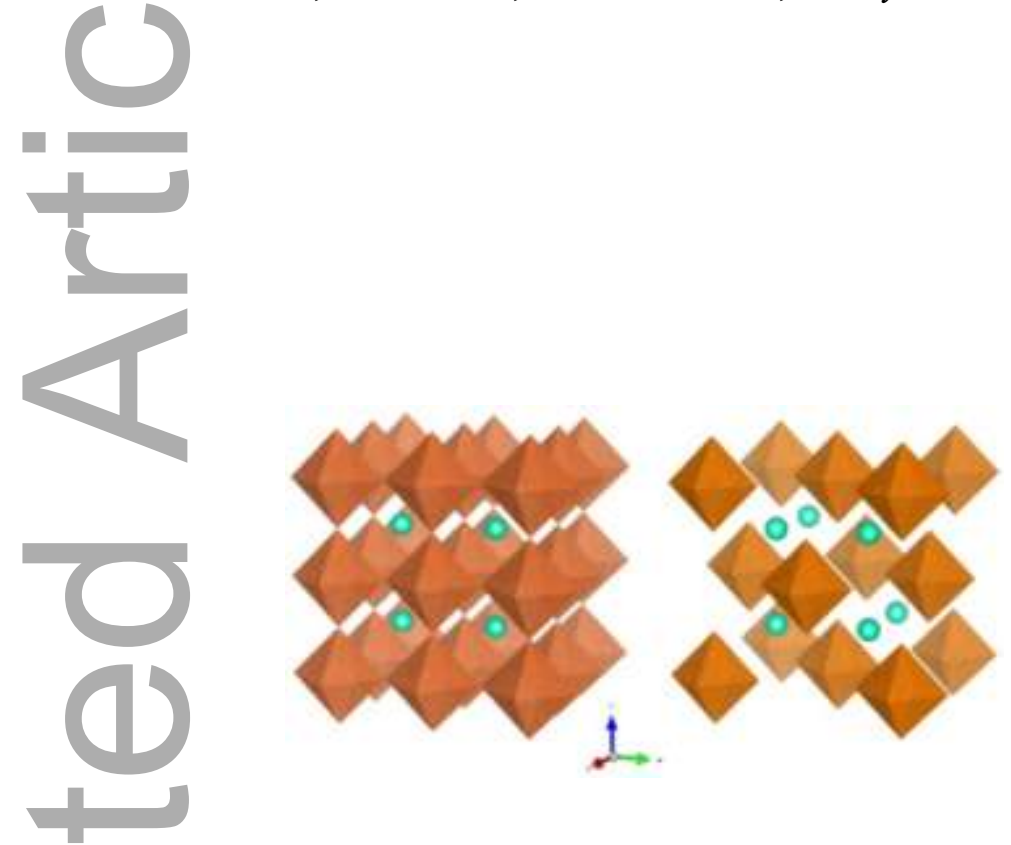

Scheme 1. Crystal structures of $\mathrm{CsSnI}_{3}$ (left) and $\mathrm{Cs}_{2} \mathrm{SnI}_{6}$ (right). Green balls represent $\mathrm{Cs}^{+}$ ions and orange octahedra represent $\mathrm{SnI}_{6}$ units. $\mathrm{Cs}_{2} \mathrm{SnI}_{6}$ crystal structure can be viewed as a derivative from $\mathrm{CsSnI}_{3}$ where every other $\mathrm{SnI}_{6}$ octahedra is removed (the oxidation state of $\mathrm{Sn}$ is consequently +2 in $\mathrm{CsSnI}_{3}$ and +4 in $\mathrm{Cs}_{2} \mathrm{SnI}_{6}$ ).

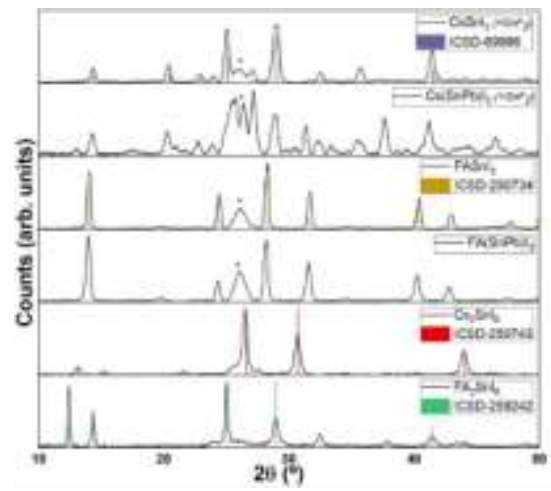




\section{WILEY-VCH}

Figure 1. XRD diffractograms of mechanochemically synthesized tin perovskites (black lines) together with reference bulk patterns from Inorganic Crystal Structure Database (ICSD; color columns). A broad peak around $2 \Theta=26^{\circ}$ and marked with an asterisk is visible in most diffractograms due to parasitic diffraction from the adhesive tape used to fix the powder samples on the substrate (see Figure S1). No reference pattern is available for mixed tin-lead perovskites. However, main peaks' positions match the reference pure-tin counterpart with a slight shift to lower angles due to the incorporation of the larger lead cation (see Figure S2).
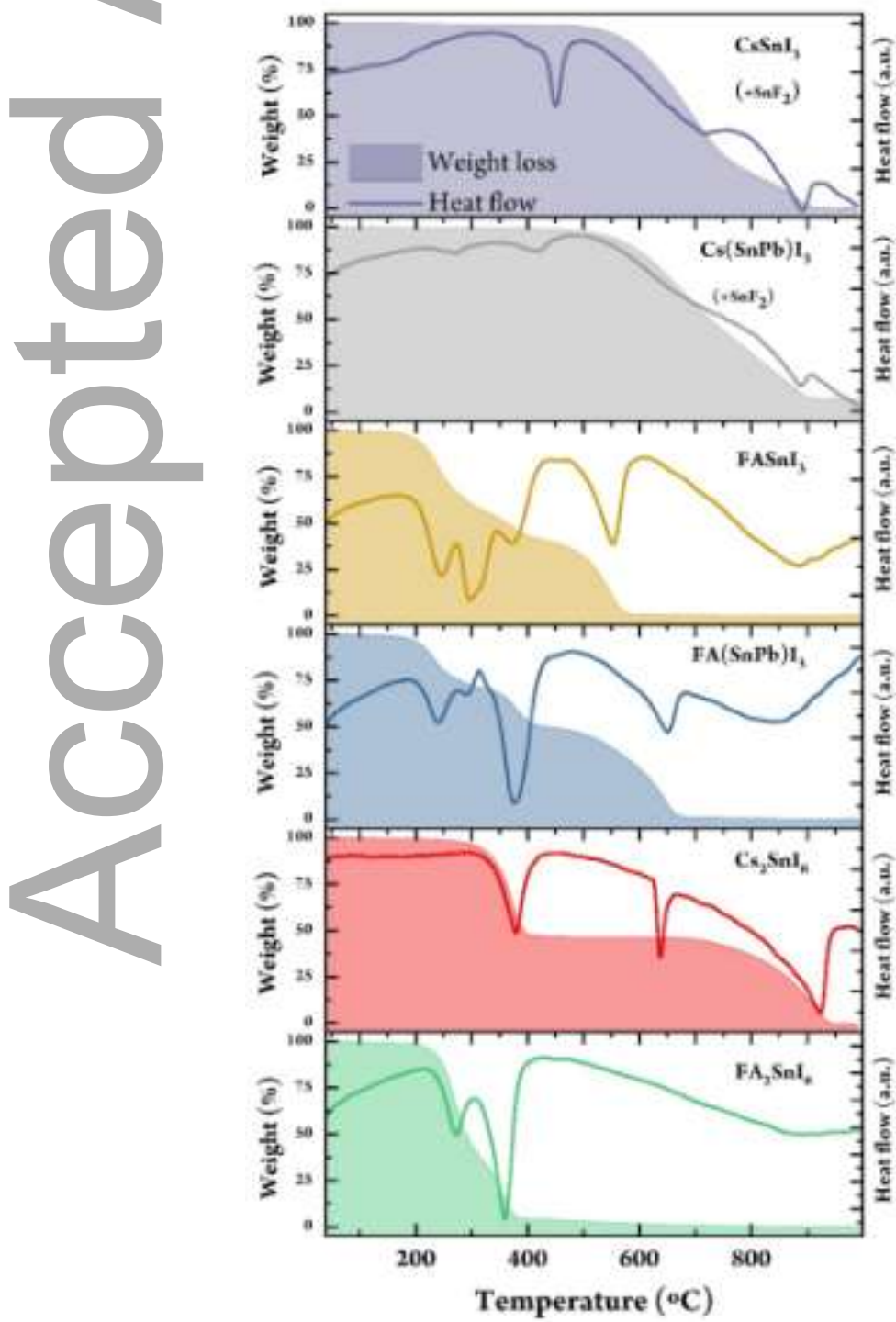

This article is protected by copyright. All rights reserved 


\section{WILEY-VCH}

Figure 2. TG (filled area) and DTA (simple line) curves of all compounds in the $40{ }^{\circ} \mathrm{C}$ to $1000{ }^{\circ} \mathrm{C}$ range.
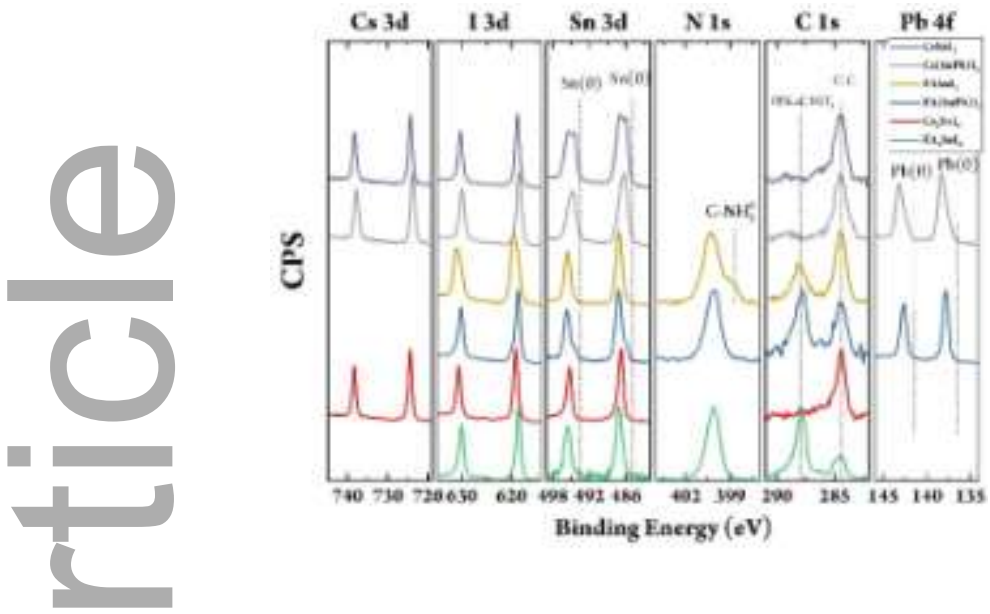

Figure 3. High-resolution XPS spectra of all main elements from the different compounds: Cs 3d, I 3d, Sn 3d, N 1s, C1s, and Pb 4f regions. Additional O 1s and F 1s spectra are given as supporting information in Figures S6 and S7.

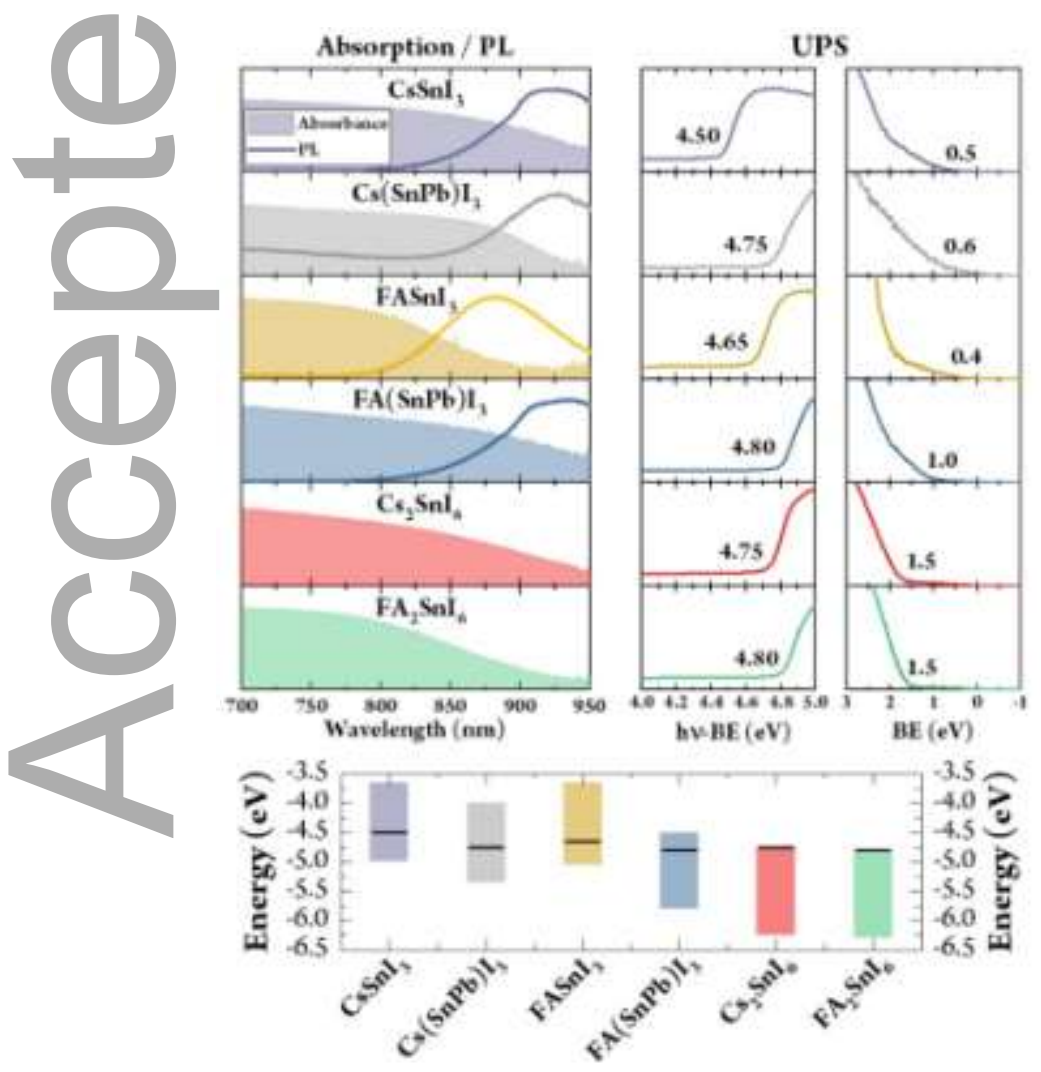

Figure 4. Optical characterization, UPS, and derived energy diagram. 

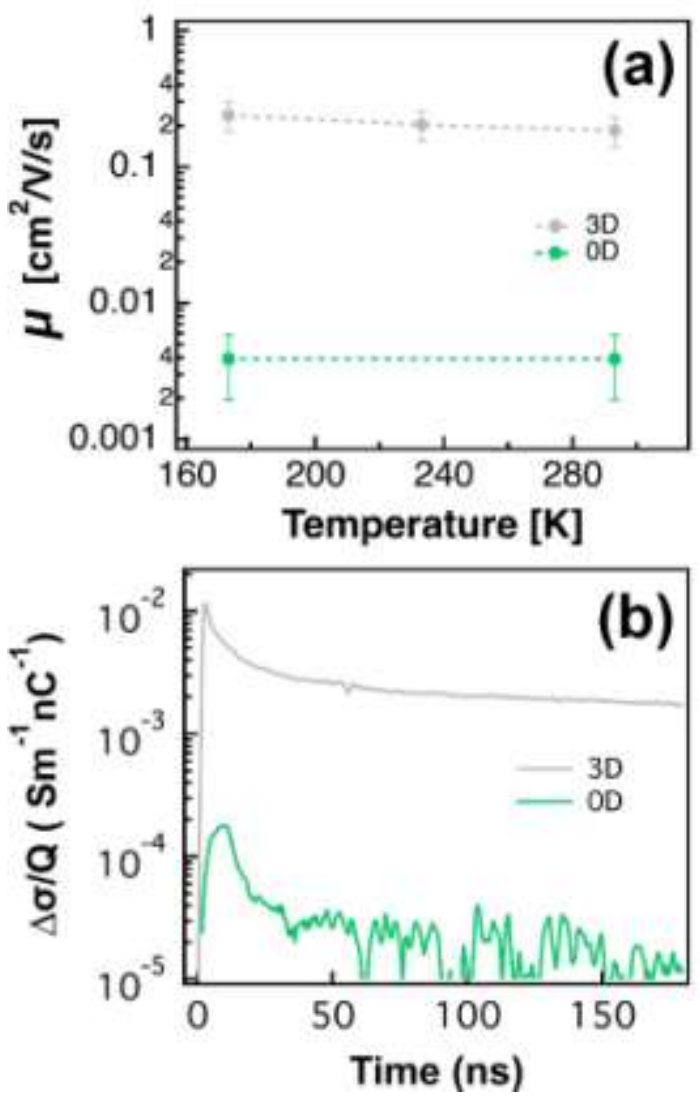

Figure 5. Mobility of charge carriers as a function of temperature (a) and change of conductivity as a function of time (b) of a $\mathrm{Sn}(\mathrm{II}) 3 \mathrm{D}$ perovskite (grey) and a $\mathrm{Sn}(\mathrm{IV}$ ) $0 \mathrm{D}$ vacancy-ordered perovskite (green).

Table 1. Atomic percentages of relevant elements based on high-resolution XPS spectra.

\begin{tabular}{|c|c|c|c|c|c|c|}
\hline 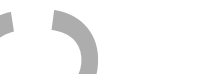 & Cs & I & Sn & $\mathbf{N}$ & $\mathbf{C}$ & $\mathbf{P b}$ \\
\hline & at. $\%$ & at. $\%$ & at. $\%$ & at. $\%$ & at. $\%$ & at. $\%$ \\
\hline $\mathrm{CsSnI}_{3}$ & 23.8 & 50.6 & 25.5 & - & - & - \\
\hline $\mathrm{Cs}(\mathrm{SnPb}) \mathbf{I}_{3}$ & 26.4 & 50.7 & 11.5 & - & - & 11.4 \\
\hline $\mathbf{F A S n I}_{3}$ & - & 25.9 & 21.2 & 34.6 & 17.7 & - \\
\hline $\mathrm{FA}(\mathrm{SnPb}) \mathbf{I}_{3}$ & - & 34.5 & 9.3 & 31.0 & 17.0 & 8.2 \\
\hline
\end{tabular}




\section{WILEY-VCH}

$\begin{array}{lllllll}\mathbf{C s}_{2} \mathbf{S n I}_{6} & 28.0 & 57.3 & 14.7 & - & - & - \\ \mathbf{F A}_{2} \mathbf{S n I}_{6} & - & 26.8 & 1.2 & 47.4 & 24.6 & -\end{array}$

\section{TOC}

Dry mechanochemical synthesis of various $\mathrm{Sn}(\mathrm{II})$ and $\mathrm{Sn}(\mathrm{IV})$ iodide perovskites are reported. As-prepared materials show excellent phase purity as determined by X-ray diffraction as well as tunable bandgap and photoluminescencence in the near-infrared. Hence, mechanochemistry appears as an ideal route to develop low-toxicity materials for optoelectronics in a solventfree approach.

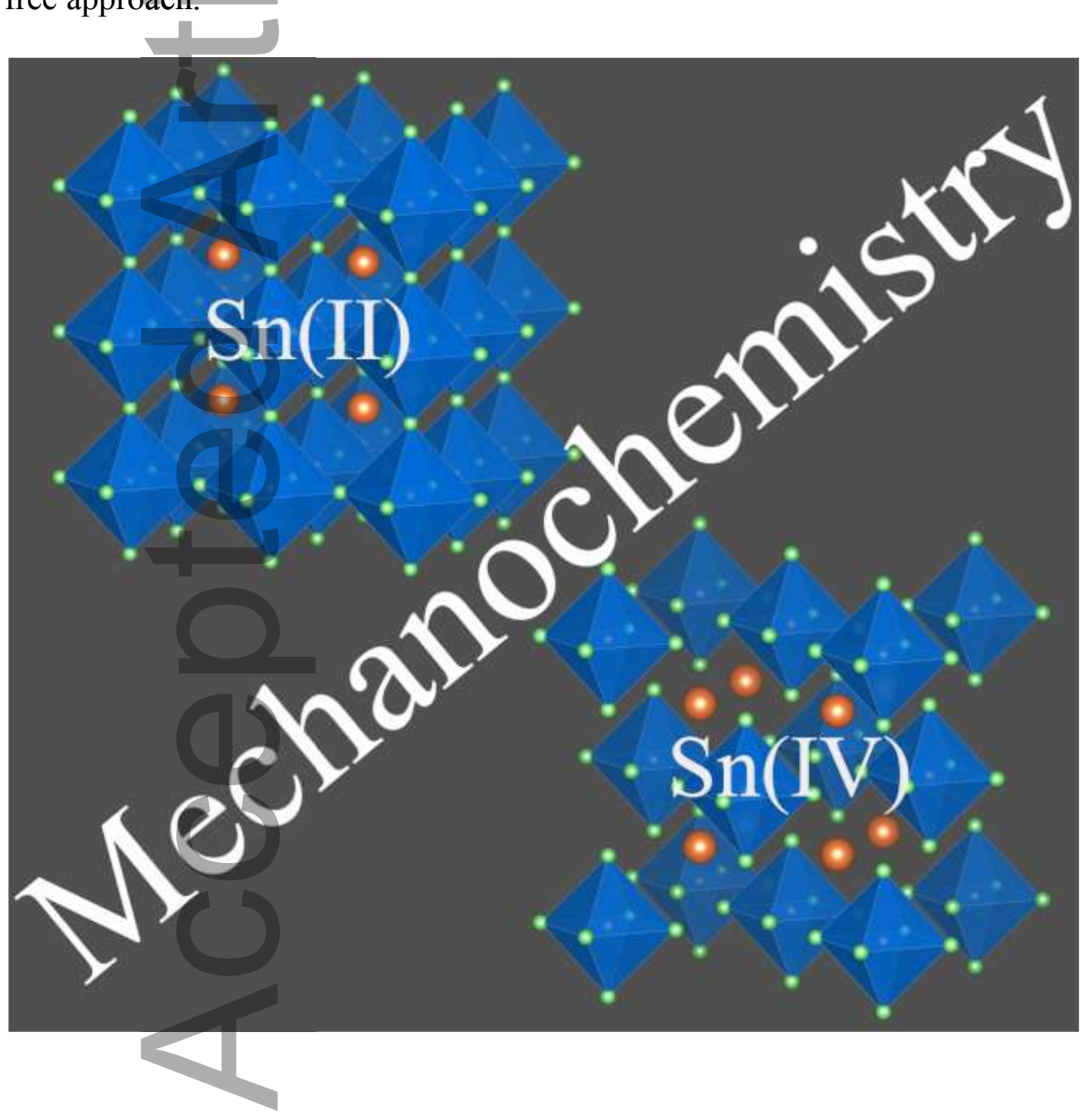

